\title{
EDITORIAL
}

\section{0 tips for intensive care management of transplanted heart patients}

\author{
Hasse Møller-Sørensen ${ }^{1 *}$, Hilde M. Norum ${ }^{2,3}$ and Sven-Erik Ricksten ${ }^{4,5}$
}

(c) 2019 Springer-Verlag GmbH Germany, part of Springer Nature

Heart transplantation (HTx) remains the definitive treatment of advanced heart failure, and survival and quality of life following HTx are excellent. The use of extended donor criteria, procurement of hearts in donation after circulatory death, and transplantation with the use of novel organ preservation techniques will possibly increase the number of organs available [1]. Globally, about half of the HTx recipients are on mechanical circulatory support, usually a left ventricular device, by the time of HTx, which augments the risk of bleeding, renal failure, and graft failure in the immediate postoperative period. If post-transplant complications are not recognized and treated promptly they might have an important negative impact on outcome. Therefore, careful monitoring and knowledge of the pathophysiology of graft failure and complications following HTx are essential for successful HTx $[2,3]$.

\section{Hemodynamic monitoring}

After HTx careful monitoring of hemodynamic parameters is necessary as even small changes in preload and afterload may impair cardiac performance and can be difficult to treat. Continuous perioperative monitoring of systemic, pulmonary artery and central venous pressure (CVP) and intermittent measurements of pulmonary capillary wedge pressure (PCWP), intermittent or continuous measurements of mixed venous oxygen saturation $\left(\mathrm{SvO}_{2}\right)$, left atrial pressure (LAP), and cardiac output (CO), in addition to standard monitoring, are recommended [2]. Ischemia and reperfusion of the graft often

\footnotetext{
*Correspondence: hassedk@gmail.com

${ }^{1}$ Department of Cardiothoracic Anesthesiology, Rigshospitalet,

Copenhagen University Hospital, Blegdamsvej 9, 2100 Copenhagen OE, Denmark

Full author information is available at the end of the article
}

induce systolic and diastolic dysfunction (Table 1, tip 1) [4]. Repeated echocardiographic assessment of heart function is necessary, especially when hemodynamic instability occurs, to diagnose ventricular under filling, tamponade or failure of, particularly, the right ventricle (RV) manifested as impaired systolic shortening of the $\mathrm{RV}$ free wall and paradoxical movement of the interventricular septum (Table 1, tip 2).

\section{Graft failure}

Early primary graft dysfunction (PGD) is associated with significantly increased 30-day and 1-year mortality and is defined as PGD diagnosed within $24 \mathrm{~h}$ of HTx. Early PGD is divided into left ventricular (LV), RV, and biventricular dysfunction and categorized according to the extent of inotropes and mechanical support used [5]. LV failure is less common than RV failure after HTx, and LV systolic dysfunction may suggest poor graft quality or acute rejection. Isolated RV failure is an independent risk factor of mortality and one of the most serious complications after HTx [4] and should be treated promptly. HTx recipients frequently exhibit increased pulmonary vascular resistance (PVR) resulting from their pre-transplant chronic heart failure or donor-recipient size mismatch. This PVR elevation may be further aggravated by cardiopulmonary bypass (CPB)-induced pulmonary endothelial dysfunction, exposure to protamine, and bleeding and blood transfusions, which may all increase the risk of postoperative RV failure. Isolated RV failure should be suspected when CVP $>15 \mathrm{mmHg}$ and/or when $\mathrm{CVP}>\mathrm{PCWP} / \mathrm{LAP}$, together with low $\mathrm{CO}$ or low $\mathrm{SvO}_{2}(<60 \%)$. Avoiding and treating $\mathrm{RV}$ failure include close attention to filling pressures and carefully maintaining an intraventricular balance with centrally aligned septum evaluated by echocardiography and a PCWP/ $\mathrm{LAP}<15 \mathrm{mmHg}, \mathrm{CVP}<\mathrm{PCWP} / \mathrm{LAP}$, and $\mathrm{SvO}_{2}>65 \%$ to ensure adequate systemic perfusion (Table 1, tip 3) [3].

\section{Springer}


Table 110 tips for intensive care management of transplanted heart patients

\begin{tabular}{ll}
\hline 1 & $\begin{array}{r}\text { Systolic and diastolic dysfunction early post-HTx are frequent and require close monitoring of left- and right-sided filling pressures, as well as } \\
\text { cardiac output and mixed venous oxygen saturation }\end{array}$ \\
2 & Repeated echocardiographic assessment of heart function is necessary, especially when hemodynamic instability occurs \\
3 & RV failure is common and therapy should aim at maintaining a CVP $<$ PCWP/LAP with a PCWP/LAP $<15 \mathrm{mmHg}$ \\
5 & Epicardial pacing to maintain heart rate at $90-110$ beats/min is recommended \\
6 & Inotropes with chronotropic entities, e.g., isoproterenol, dopamine, dobutamine, or milrinone, are recommended $>24$ h post-HTx \\
7 & In severe RV failure, inhaled therapies with nitric oxide or prostacyclin, enable selective pulmonary vasodilation and unloading of the failing RV \\
8 & In severe graft failure, early initiation of mechanical support is indicated \\
9 & Infusion of natriuretic peptide may reduce the need for dialysis in selected HTx patients with associated AKI \\
10 & Everolimus-based immunosuppression with early cessation of calcineurin inhibitor is beneficial for kidney function \\
\hline
\end{tabular}

As a result of the autonomically denervated heart, sinus bradycardia and supraventricular arrhythmias are common rhythm disturbances after HTx [6]. Heart rate (HR) early post-HTx is a significant driver of $\mathrm{CO}$ because of diastolic dysfunction. Atrial pacing is therefore initiated by surgically placed pacing wires to maintain HR 90-110 beats/min (Table 1, tip 4). Persistent tachyarrhythmias should prompt investigation of possible rejection and treated accordingly.

Most patients receive inotropes for chronotropic and inotropic stimulation of the denervated heart. To avoid RV failure, we routinely use infusion isoproterenol for a minimum of $24 \mathrm{~h}$ to decrease PVR and to increase myocardial contraction and HR. Standard inotropic medication includes a combination of isoproterenol, dopamine, dobutamine, or milrinone [2] (Table 1, tip 5). Normally, the inotropic support is weaned over $2-4$ days post-HTx. Norepinephrine may be added to achieve a mean arterial pressure $>65 \mathrm{mmHg}$ if tolerated; otherwise an individualized arterial pressure to obtain optimal balance between systemic and cardiac pressures is sought. A hesitance to treat systemic vasodilation with norepinephrine fearing that norepinephrine will provoke RV failure by pulmonary vasoconstriction is not supported by the literature, as norepinephrine does not increase PVR in postcardiotomy vasodilatory shock (Table 1 , tip 6) [7]. Most patients can be handled conservatively with inotropic and/or vasoactive infusions, but in more severe RV failure, adjunctive therapy with inhaled nitric oxide or prostacyclin, to enable selective pulmonary vasodilation and thereby decreasing PVR and RV afterload, may be indicated (Table 1, tip 7) [8]. In case of severe graft failure despite vasoactive and inotropic support, early initiation of mechanical support is indicated (Table 1, tip 8) [9].

\section{Renal function}

Acute kidney injury (AKI) after HTx is a common complication with an incidence of $25-50 \%$ and an incidence of dialysis-dependent AKI of 12-22\%. Impaired renal oxygen delivery during $\mathrm{CPB}$ [10], bleeding/tamponade, postoperative RV failure, and venous congestion [11] as well as the use of calcineurin inhibitors (CNI) are all linked to post-HTx AKI. In early AKI post-HTx, infusion of low-dose (50 ng/ $\mathrm{kg} / \mathrm{min}$ ) atrial natriuretic peptide (ANP) increases renal blood flow and glomerular filtration rate and decreases the incidence of dialysis in AKI after cardiac surgery. A meta-analysis showed that for solid organ (liver, heart, kidney) transplantation-associated AKI, ANP reduces the need for dialysis (Table 1, tip 9) [12].

\section{Immunosuppression}

Effective immunosuppression protects against acute and chronic graft rejection and is a prerequisite for successful HTx, but has feared side effects like susceptibility to infections and malignancies. For intense immunosuppression immediately post-HTx, $50 \%$ of HTx recipients receive induction therapy with anti-thymocyte or antilymphocyte globulins, or interleukin-2 receptor antagonists, the former of which is associated with better long-time survival [13]. CNIs, included in standard immunosuppressive regimens, are nephrotoxic.

\section{Management of immunosuppression related complications}

Aiming at minimizing the risk of CNI-related complications and worsening of pre-HTx comorbidities, induction therapy may allow for postponing of CNI exposure, of special relevance to HTx recipients with impaired kidney function [14]. Everolimus, a proliferation signal inhibitor, may be an alternative to $\mathrm{CNI}$ in de novo heart transplant recipients, as everolimus-based immunosuppression with early elimination of CNI is associated with longterm preservation of kidney function [15], and may be relevant to avoid renal replacement therapy and its associated increased in-hospital mortality (Table 1, tip 10). 


\section{Author details}

1 Department of Cardiothoracic Anesthesiology, Rigshospitalet, Copenhagen University Hospital, Blegdamsvej 9, 2100 Copenhagen OE, Denmark. ${ }^{2}$ Research Institute of Internal Medicine, Oslo University Hospital Rikshospitalet, Oslo, Norway. ${ }^{3}$ Department of Research and Development, Division of Emergencies and Critical Care, Oslo University Hospital, Oslo, Norway. ${ }^{4}$ Department of Cardiothoracic Anaesthesia and Intensive Care, Sahlgrenska University Hospital, Gothenburg, Sweden. ${ }^{5}$ Department of Anesthesiology and Intensive Care Medicine, Sahlgrenska Academy, University of Gothenburg, Gothenburg, Sweden.

\section{Compliance with ethical standards}

\section{Conflicts of interest}

The authors declare they have the following conflicts of interest: HMS has no conflicts of interest. SER and HMN have received lecture fees from Orion Pharma.

\section{Ethical approval}

An approval by an ethics committee was not applicable.

\section{Publisher's Note}

Springer Nature remains neutral with regard to jurisdictional claims in published maps and institutional affiliations.

\section{Received: 7 November 2018 Accepted: 23 January 2019}

Published online: 6 February 2019

\section{References}

1. European Directorate for the Quality of Medicines and HealthCare. Guide to the quality and safety of organs for transplantation. 7th ed. Strasbourg: EDQM; 2018

2. Costanzo MR, Dipchand A, Starling R, Anderson A, Chan M, Desai S et al (2010) The International Society of Heart and Lung Transplantation guidelines for the care of heart transplant recipients. J Heart Lung Transplant 29(8):914-956

3. Birati EY, Rame JE (2014) Post-heart transplant complications. Crit Care Clin 30(3):629-637

4. Segovia J, Pulpon LA, Sanmartin M, Tejero C, Serrano S, Burgos R et al (1998) Primary graft failure in heart transplantation: a multivariate analysis. Transplant Proc 30(5):1932
5. Kobashigawa J, Zuckermann A, Macdonald P, Leprince P, Esmailian F, Luu M et al (2014) Report from a consensus conference on primary graft dysfunction after cardiac transplantation. J Heart Lung Transplant 33(4):327-340

6. von Scheidt W, Bohm M, Schneider B, Autenrieth G, Erdmann E (1992) Cholinergic baroreflex vasodilatation: defect in heart transplant recipients due to denervation of the ventricular baroreceptor. Am J Cardiol 69(3):247-252

7. Redfors B, Bragadottir G, Sellgren J, Sward K, Ricksten SE (2011) Effects of norepinephrine on renal perfusion, filtration and oxygenation in vasodilatory shock and acute kidney injury. Intensive Care Med 37(1):60-67

8. Ardehali A, Hughes K, Sadeghi A, Esmailian F, Marelli D, Moriguchi J et al (2001) Inhaled nitric oxide for pulmonary hypertension after heart transplantation. Transplantation 72(4):638-641

9. Takeda K, Li B, Garan AR, Topkara VK, Han J, Colombo PC et al (2017) Improved outcomes from extracorporeal membrane oxygenation versus ventricular assist device temporary support of primary graft dysfunction in heart transplant. J Heart Lung Transplant 36(6):650-656

10. Lannemyr L, Bragadottir G, Krumbholz V, Redfors B, Sellgren J, Ricksten SE (2017) Effects of cardiopulmonary bypass on renal perfusion, filtration, and oxygenation in patients undergoing cardiac surgery. Anesthesiology 126(2):205-213

11. Aneman A, Brechot N, Brodie D, Colreavy F, Fraser J, Gomersall C et al (2018) Advances in critical care management of patients undergoing cardiac surgery. Intensive Care Med 44(6):799-810

12. Nigwekar SU, Kulkarni H, Thakar CV (2013) Natriuretic peptides in the management of solid organ transplantation associated acute kidney injury: a systematic review and meta-analysis. Int J Nephrol 2013:949357

13. Ansari D, Lund LH, Stehlik J, Andersson B, Hoglund P, Edwards L et al (2015) Induction with anti-thymocyte globulin in heart transplantation is associated with better long-term survival compared with basiliximab. J Heart Lung Transplant 34(10):1283-1291

14. Fortrie G, Manintveld OC, Caliskan K, Bekkers JA, Betjes MG (2016) Acute kidney injury as a complication of cardiac transplantation: incidence, risk factors, and impact on 1-year mortality and renal function. Transplantation 100(8):1740-1749

15. Andreassen AK, Andersson B, Gustafsson F, Eiskjaer H, Radegran $G$, Gude E et al (2016) Everolimus initiation with early calcineurin inhibitor withdrawal in de novo heart transplant recipients: 3 -year results from the randomized SCHEDULE study. Am J Transplant 16(4):1238-1247 